\title{
O Ideal transcendental da razão em Kant e a génese das explicações míticas
}

\author{
António Machuco Rosa
}

\section{Introdução}

Obra capital da história da Filosofia, a Crítica da Razão Pura não pode contudo deixar de ter subjacente o contexto histórico da estrutura do conhecimento que lhe é contemporânea. Isso deve levar a reconhecer que a argumentação desenvolvida por Kant pode, e por vezes deve, ser adaptada e reformulada em função de outros contextos de conhecimento, o que inevitavelmente acarreta algumas reorganizações da estrutura geral da Crítica da Razão Pura. Mais especificamente, é sobejamente conhecido como a geometria e a fisica de Newton, por um lado, e a metafísica clássica, por outro, formam o contexto no qual a teoria do conhecimento de Kant assenta. A separação entre esses dois domínios do saber foi sublinhada com nitidez pelo filósofo alemão e, em linhas gerais, a necessidade de a traçar mantém-se mesmo após o desenvolvimento da física e da matemática ao longo dos três últimos séculos. Contudo, sustentaremos neste artigo que existem certos aspectos pensados por Kant no quadro da metafisica clássica que podem ser reavaliados e reformulados à luz de quadros teóricos mais recentes.

Serão analisadas certas ideias chave avançadas por Kant na 'Dialéctica transcendental' da Crítica da Razão Pura, mais particularmente, será analisada a afirmação segundo a qual existe uma aparência transcendental ou ilusão natural da razão, cujos mecanismos de génese Kant se propõe elucidar no capítulo intitulado 'O Ideal da razão pura'. A primeira secção do presente artigo descreve o quadro geral da argumentação da 'Dialéctica transcendental', tendo em vista analisar, na segunda secção, o argumento com o qual Kant busca explicar a existência na razão humana da aparência transcendental, isto é, de uma tendência natural e inevitável para imaginar certas entidades singulares capazes de determinar completamente a realidade. Concluiremos então que $o$ argumento de Kant pode ser reformulado, tornando mais inteligiveis os reais mecanismos subjacentes a essa tendência inevitável. Será esse o objecto da terceira secção, na qual se mostrará poder partir-se, não, como Kant fez, da lógica, mas sim da geometria utilizando a teoria dos autómatos celulares - para fundar o mecanismo de emergência de entidades singulares e globais a partir de uma realidade distribuída. Trata-se, no sentido próprio do termo, da emergência de entidade imaginárias que, como Kant sublinhou, são coisas em si que decorrem da finitude da razão. É a geometrização dessa finitude que permite reformular o argumento dessa parte central da Crítica da Razão Pura que é constituída pelo capitulo acerca do 'Ideal da razão pura'. 


\section{A estrutura geral da 'Dialéctica transcendental'}

A primeira secção da 'Dialéctica transcendental' da Crítica da Razão Pura sublinha desde o seu início que a razão humana, enquanto faculdade de conhecer, gera constantemente uma ilusão, designada por aparência transcedental. Trata-se de uma ilusão que não pode ser evitada, 'uma ilusão natural e inevitável' (A 297 / B 353)', , sendo precisamente objectivo principal da dialéctica transcendental explicar a sua emergência. Resumindo desenvolvimentos futuros, Kant refere que a fonte dessa aparência e ilusão reside no uso ilegítimo das funções de cada faculdade do conhecimento, residindo em particular numa extensão do entendimento puro que faz com que aquilo que não é senão um princípio subjectivo passe por uma determinação objectiva das coisas em si. As restantes secções da 'Dialéctica transcendental' mostrarão como os grandes temas da metafísica clássica giram em torno desse uso ilegítimo, mas parece-nos indiscutível ser sobretudo no capítulo 'O Ideal da razão pura' que Kant verdadeiramente busca as fontes da aparência transcendental. É igualmente claro que a argumentação de Kant exige uma rápida identificação dos pontos mais importantes abordados na 'Dialéctica transcendental'.

Recorde-se que após ter tratado, na 'Analítica transcendental', das funções do entendimento, Kant analisa na 'Dialéctica transcendental' as funções da razão. A razão possui sobretudo um uso lógico. Mais exactamente, e no contexto da 'Dialéctica transcendental', o uso lógico da razão concerne a sua relação ao uso lógico do entendimento, este último caracterizado pelos tipos de raciocínios lógico-formais que Kant julgava imutáveis na medida em que sintetizavam os resultados definitivos que a própria lógica formal podia atingir. Na sua relação à razão, o entendimento já não funciona de acordo com a sua relação às formas da sensibilidade (e por via destas à geometria), pelo que o uso lógico da razão é puramente conceptual e simbólico, traduzindo-se finalmente na existência de três tipos de raciocínios, os raciocínios categóricos, hipotéticos e disjuntivos (A 304 / B 361). Isso significa que, tal como a tabela dos juízos da lógica formal serve de guia à formulação das categorias do entendimento, também os raciocínios ou inferências formais vão servir de base à formação das ideias transcendentais da razão, também designadas por conceitos puros da razão.

A razão forma as ideias transcendentais quando, a partir dos três tipos de raciocínios mencionados, busca o incondicionado, o qual é caracterizado como aquilo que não depende de qualquer condição. Uma condição é uma premissa (um juízo), e o entendimento trata apenas da relação de inclusão entre as condições, isto é, ele subsume o particular (uma premissa menor num raciocínio de tipo silogístico) sob o universal (a premissa maior), a subsumpção designando usualmente a regra de inferência que formalmente valida o raciocínio em questão ${ }^{2}$. Pelo contrário, utilizando as significativas metáforas de Kant, a razão busca o incondicionado através de um percurso ascendente de generalização que visa obter a unidade sistemática da própria razão. Essa generalização (cf. A 306 /B 363 e A 323 /B 379) consiste em partir de certas premissas de um raciocínio, por exemplo de 'todos os portugueses são mortais', a qual pode ser provada (tornando-se uma conclusão) com a asserção das premissas 'todos os animais são mortais' e 'todos os portugueses são animais'. A generalização consiste em que ‘todos os animais são mortais' é uma premissa que permite não apenas provar que 'todos os portugueses são mortais' mas também, por exemplo, que ‘todos os homens são mor-

1 Seguimos a prática usual de referir a Kritik der Reinen Vernunft através dos números de páginas das $1^{*}$ e $2^{*}$ edições. As traduções tomaram em consideração a edição portuguesa: I. Kant, Crítica da Razão Pura, Lisboa, F. Gulbenkian, 1997, tradução de Manuela P. Santos e Alexandre Morujão.

2 Veja-se a Lógica de Kant para as regras de inferência que, na perspectiva da lógica clássica, validam os raciocínios categóricos (Logik § 63), hipotéticos (Logik § 75) e disjuntivos (Logik $\S 78)$. No contexto do presente artigo, são irrelevantes os habituais argumentos dirigidos contra a síntese que Kant faz da lógica clássica. 
tais'. Poder-se-ia afirmar que, em estritos termos de lógica formal, a argumentação de Kant não parece ter muito sentido, pois substituindo variáveis ao modelo semântico que utilizámos constata-se de imediato que a máxima generalidade lógica já está atingida ${ }^{3}$. Só que isso implica esquecer, como por vezes foi feito, que Kant tem em vista não apenas a lógica formal mas sobretudo a lógica reportada ao conhecimento de objectos ('lógica transcendental'), donde, nesse caso, se tratar da busca ascendente de condições em vista a obter o incondicionado, sendo certo que se a relação de algo condicionado a uma condição pode ser analítica, já a relação a um incondicionado que encerra em si mesmo a série total das condições é sintética (A 308 / B 364). A lógica formal (clássica ou moderna) não fornece um tal incondicionado e, na realidade, como Kant salienta, um tal objecto infinito está completamente fora de qualquer experiência possível.

Mais especificamente, a generalização até ao incondicionado é levada a cabo de três formas, correspondendo aos raciocínios categóricos, hipotéticos e disjuntivos. No primeiro caso, obtém-se um incondicionado que é 'um sujeito que ele próprio não é predicado'. No segundo, o incondicionado é 'uma pressuposição que não pressupõe mais nada', e, no terceiro, é 'um agregado dos membros da divisão que não exige mais nada para a divisão de um conceito' (A 323 / B 379). É dessa forma que se obtém o sistema das ideias transcendentais, as quais recapitulariam grande parte da metafísica clássica. A generalização categórica conduz à Psicologia e à Ideia de um Eu simples, a generalização Hipotética à Cosmologia e à Ideia de um Mundo sem começo no tempo, etc., e a generalização disjuntiva à Teologia e à Ideia de um ser supremo, o qual pode ser Deus. É conhecido que, para Kant, a primeira dessas ideias conduz a paralogismos, enquanto a segunda gera antinomias, pois a busca dessa série ascendente leva a pensar que essa totalidade de condições pode ser dada experiência, quando de facto não pode, e tudo o que resta são os insanáveis conflitos dialécticos da razão.

$\mathrm{O}$ incondicionado que aqui mais nos interessa analisar é o que corresponde à terceira Ideia, ou conceito puro de um ser simples sem predicados logicamente divisíveis sob forma disjuntiva. Kant trata da origem dessa ideia no capítulo $\mathrm{O}$ Ideal da razão pura', o qual surge na Crítica da Razão Pura após a exposição dos paralogismos da psicologia e das antinomias cosmológicas da razão, precedendo o capítulo onde se examinam as provas da existência de Deus. Sendo certo que a argumentação de Kant deve ser vista no contexto da teologia e da história da metafísica clássica, mostraremos que ela ultrapassa esse estrito domínio, pelo que a 'ilusão necessária' designa de facto, como Kant insiste, uma operação bastante geral da razão, da qual a génese da ideia de Deus é apenas uma das principais manifestações. Vejamos pois com algum detalhe a argumentação desenvolvida em o 'Ideal da Razão Pura'.

\section{O Ideal da Razão Pura}

Como recorrentemente sucede na Crítica da Razão Pura, a argumentação de Kant gira em torno da separação das faculdades de conhecimento e dos objectos sobre os quais cada uma exerce a sua jurisdição. Por exemplo, a razão forma a noção de certas entidades singulares, e quando o faz não exerce apenas a sua jurisdição sobre Ideias, as quais não se aplicam à experiência empírica, in concreto, mas visa igualmente um ideal, o qual é a apresentação de uma ideia não apenas in concreto mas também in individuo, isto é, uma entidade singular absolutamente determinada apenas pela própria ideia (A 568 / B 596). É através desse tipo de ideal que a razão procura a determinação

3 Em linguagem moderna, parte-se de $\mathrm{x}(\mathrm{Hx} \rightarrow \mathrm{Gx})$ ('todos os portugueses são mortais') e assere-se $x(F x \rightarrow G x)$ e $x(H x \rightarrow F x)$, logo $x(H x \rightarrow G x)$. Naturalmente que já se encontrou a máxima generalidade formal de um juízo categórico, sendo irrelevante a substituição uniforme das letras de predicado. 
completa dos seus objectos (Ibidem), sendo nesse conceito de determinação completa que a argumentação se baseia. Como também usualmente sucede em Kant, esse conceito é inicialmente analisado do ponto de vista do entendimento na sua função puramente lógico-formal e, de seguida, da sua ligação à sensibilidade, remetendo-se neste último caso para a lógica transcendental. Na primeira acepção, refere-se que um conceito pode ser determinado através do princípio do terceiro excluído, p v p p, que Kant faz derivar do princípio de não contradição (A 1193 / B 599) ${ }^{4}$. A forma disjuntiva traduz de forma clara a princípio de determinação completa, devendo notar-se que, em lógica moderna, ela apenas é possível com o comprometimento ontológico que afirma a existência de um conjunto infinito actual de indivíduos aos quais inerem predicados.

A perspectiva da lógica transcendental é diferente. A 'Dialéctica transcendental' sustenta que não se deve admitir um tal conjunto, e na realidade a análise de Kant do conceito de determinação completa não parte de qualquer conjunto logicamente consistente de indivíduos ou predicados dados (uma estrutura semântica, na linguagem da lógica moderna), mas sim da própria coisa, isto é, estamos no âmbito da lógica transcendental. Como Kant também insistentemente sublinhou, uma coisa não pode ser dada conceptualmente nem logicamente deduzida (não é um conceito analítico). A coisa tem de ser posta, ela é dada numa realidade insistente sobre o aparelho perceptivo de um sujeito sob a forma, não conceptual, do choque da percepção sensorial ou do choque da resistência física. Portanto, a determinação completa de uma coisa não se baseia na comparação lógica de predicados, avaliando a sua consistência através do princípio de não contradição, mas sim na comparação da própria coisa ao conjunto de todos os predicados possíveis (A 573 / 601). Ora, e independentemente de facto de para a lógica moderna poder ou não fazer sentido falar de 'um conjunto de todos os predicados', isto é, de um conjunto infinito actual, é sublinhado por Kant que um tal conjunto não pode ser apresentado in concreto na experiência.

No entanto, e apesar disso, a razão forma contínua e indiscutivelmente essa ideia, da qual exclui os predicados que se apresentam sob a forma de negações (transcendentais, e não as negações automaticamente geradas pela lógica formal) (A 573 / B 602). A razão forja assim o ideal transcendental, isto é, a ideia in individuo de um ser singular, o qual é fundamento de toda a realidade e no qual não existem negações (A 575 / B 603). Trata-se do ens realissimum da metafísica clássica, o qual é fundamento da determinação completa não apenas de cada coisa mas também das coisas em geral (A 576 / B 604). Ele é a premissa incondicionada que por generalização se atinge através de raciocínios disjuntivos (Ibidem) e é pensado por analogia com uma coisa, só que se trata de 'uma coisa que é uma pura ficção' (A 580 / B 609). É uma coisa em si, sendo importante referir que essa entidade singular não é o agregado de todas as coisas mas sim o seu fundamento (A 579 / B 607). Portanto, a totalidade da realidade encontrar-se-ia presente numa entidade ideal na qual todos os predicados estariam fundidos e que, ilusoriamente, seria pensada como a causa singular de todos eles. Iremos ver como se pode formar essa entidade imaginária e singular determinada como indivíduo existente apenas em virtude da sua própria ideia.

O capítulo sobre o ideal da razão pura é efectivamente o momento fundamental da dialéctica transcendental. Como atrás se referiu, no início da segunda parte da Crítica da Razão Pura afirma-se que a ilusão necessária da razão consiste em tomar como uma necessidade objectiva da determinação das coisas em si o que mais não são que certas operações levadas a cabo pelo entendimento (A 297 / B 354). Mas no capítulo sobre o ideal da razão pura o objectivo já não é apenas descrever os procedimentos dialécticos da razão (como sucede na exposição dos paralogismos e das antinomias); 'é necessário também tentar descobrir as suas fontes para poder explicar essa aparência como um fenómeno do entendimento, pois o ideal de que falamos está fundado numa

4 Mas na Lógica $§ 78$ Kant sustenta que a regra que valida os raciocínios disjuntivos é o princípio do terceiro excluído. 
ideia natural e não meramente arbitrária' (A 581 /B 609). A questão que Kant coloca é então saber como se forma essa ideia natural (Ibidem). A argumentação (A 581 /B 609 A 583 /B 601) é bastante densa e, mesmo se acabarmos por concluir que ela não é completamente decisiva, torna-se necessário expô-la com algum detalhe.

Deve-se, (i), partir da realidade do fenómeno, o real dado na própria coisa e que é fundamento da sua percepção. É uma realidade não conceptual mas que serve de base para a determinação conceptual dos fenómenos. Ora, (ii), um objecto dos sentidos apenas pode ser completamente determinado quando ele é comparado à totalidade dos predicados possíveis, negando ou afirmando a inerência ao objecto de cada um desses predicados; a determinação completa é um conceito limite que permite assimptoticamente caracterizar a coisa na sua unicidade e singularidade. Mas, (iii), tal como o real da coisa tem de ser dado para que esta possa ser pensada sob a forma de predicados que lhe são inerentes, também o real de todos os fenómenos é dado sob a forma 'da experiência única e compreendendo tudo'. Esta experiência é 'a matéria para a possibilidade de todos os objectos dos sentidos', sendo na sua limitação que se baseia a possibilidade desses mesmos objectos. Esta espécie de matéria-fundamento da possibilidade de todos os objectos não é um conceito de interpretação imediatamente clara, mas não parecem restar dúvidas de que ele designa o real em geral, isto é, o facto de as coisas em geral aparecem e estarem presentes numa consciência. É evidente que por essa matéria-fundamento Kant não entende o real dado de cada coisa dada particularmente. A matéria-fundamento é um datum ou fundamento do poder denotativo em geral da mente; ela é aquilo que está presente em geral, sendo um mero ISSO sem determinações específicas $^{5}$. Esse ISSO [etwas], essa realidade em geral, e o sublinhado é de Kant, torna possível para nós um objecto (A 582 / B 610), isto é, a matéria-fundamento é a própria realidade exterior em geral tal como ela aparece ou está presente numa consciência; noutros termos, ela não é uma coisa em si. É então, (iv), que intervém aquilo que Kant designa por uma sub-repção da razão, sendo nela que reside a fonte da ilusão natural e da aparência transcendental: a ilusão natural consiste na aplicação às coisas em geral dessa 'experiência única e total', a qual no entanto não se aplica senão aos objectos dos sentidos, isto é, à realidade para nós. A raiz da ilusão consistirá portanto, inicialmente, em imaginariamente se transformar aquilo que, mesmo que denotando uma realidade exterior, tem realidade objectiva apenas enquanto dado na consciência de um sujeito, numa coisa em si completamente independente do sujeito. De seguida, essa coisa em si, a realidade imaginada como completamente independente do sujeito, é determinada de modo puramente conceptual com base no pensamento lógico-simbólico. Por exemplo, utilizando raciocínios disjuntivos para a determinação das coisas em geral ou atribuindo a certas entidades predicados como 'totalidade', simplicidade', etc., os quais não podem ser objecto de qualquer experiência possível.

Mesmo que a anterior argumentação permita eventualmente aclarar a origem de certos raciocínios dialécticos e mostrar as aparências envolvidas na utilização do pensamento puramente conceptual, ela não parece satisfazer todos os requisitos explicativos que Kant se impôs. De entre as objecções possíveis, pode referir-se que ela seguramente não torna inteiramente claro como se forma a noção de certas entidade singulares encerrando em si uma determinação completa da realidade. Nem parece que se tenha apurado a génese de certas entidades propriamente designadas como imaginárias, mas cuja ficção emerge a partir de mecanismos efectivamente presentes na experiência possível, e não apenas a partir da ficção de uma realidade independente e em si que se procura caracterizar em termos puramente conceptuais. Na verdade, o próprio Kant parece ter estado consciente da insuficiência da sua argumentação e de objecções como as acabadas de referir pois ele acrescenta um novo parágrafo à derivação anteriormente exposta. Esse parágrafo é para nós decisivo, parecendo que ele é efectiva-

s. Cf. C. S. Peirce, 'Uma Nova Lista de Categorias', in Charles S. Peirce-Antologia Filosófica, António Machuco Rosa (ed.), Lisboa, IN-CM, 1998, p. 15. 
mente necessário para complementar a explicação acerca da emergência de certas entidade singulares imaginárias. Esse parágrafo encerra o capítulo acerca do ideal transcendental e citamo-lo na íntegra:

Se, além disso, hipostasiamos essa ideia de conjunto de toda a realidade, isso deve-se a transformarmos dialecticamente a unidade distributiva do uso experimental do entendimento numa unidade colectiva de um todo da experiência, e que nesse todo do fenómeno nós pensamos uma coisa singular, que contém em si toda a realidade empírica, e que, através da sub-recepção transcendental já mencionada, acaba por se confundir com o conceito de uma coisa situada no cima da possibilidade de todas as coisas, que dele obtêm as condições reais da sua determinação completa. (A 582-3/B 610-11).

Um ponto deve desde logo ser mencionado: estruturalmente existem duas partes na argumentação do parágrafo. Na primeira parte é explicada a hipóstase, e na segunda é acrescentado que a entidade ou coisa singular hipostasiada é tornada, por sub-recepção, a possibilidade da determinação completa de todas as coisas. Essa estrutura mostra que esse parágrafo visa responder mais cabalmente às fontes da ilusão natural da razão, somente agora se mostrando como se converte um 'conjunto de toda a realidade' numa entidade singular que é o fundamento de todas as coisas.

Esse importante ponto sublinhado, vejamos o conteúdo da citação. Surge então uma tarefa que não parece ser muito fácil: elucidar o significado dos termos sublinhados por Kant, 'distributiva' e 'colectiva'. Essa tarefa não é fácil desde logo por apenas termos conseguimos identificar uma outra passagem da Crítica da Razão Pura onde Kant utiliza tais conceitos (A 644 / B 672), a qual no entanto pouco esclarece. Sugere-se no entanto que nos podemos inicialmente guiar pela tábua dos juízos (A 70 / B 95) e afirmar que a 'unidade distributiva' se reporta aos juizos vistos do ponto de vista da sua quantidade e, dentro destes, aos juízos universais, a que, na tábua das categorias, corresponde a categoria da unidade. Quando à 'unidade colectiva', ela reporta-se, sempre nos juízos vistos do ponto de vista da sua quantidade, aos juízos singulares, a que corresponde a categoria de totalidade. Julgamos poder ainda ser mais precisos, sustentando a hipótese segunda a qual deve ser a lógica clássica, em particular a lógica medieval, a servir de guia para uma elucidação completa dos conceitos em questão é perfeitamente conhecido que o sistema de lógica de Kant mais não pretendia que ser uma recapitulação da história da lógica clássica. Ora, no quadro da tradição lógica medieval das Proprietates Terminatum, utilizou-se inicialmente a palavra distributio para significar a aposição do que hoje chamamos um quantificador universal, 'mas que mais tarde acabou por designar a propriedade que se supõe que um termo geral tem quando é usado para representar todos os indivíduos aos quais é aplicável'6. Os mesmo lógicos, tal como mais tarde Kant, assimilavam os juízos singulares aos juízos universais $^{7}$ e, mais especificamente, consideravam também um juizo colectivo como uma espécie de juízo singular ${ }^{8}$. Isso esclarece o sentido de 'distributivo' e 'colectivo' em Kant: a universalidade é distribuída por cada um dos indivíduos aos quais o predicado se aplica (em termos modernos, 'tome-se um qualquer x e então $\mathrm{x}$ verifica o predicado F'). Note-se que isso não implica a formação de totalidades ilegítimas, nem tão pouco

6 Cf. W. Kneale \& M. Kneale, O Desenvolvimento da Lógica, Lisboa, F. Gulbenkiam, 1980 p. 278.

7 Cf. Kant, Logik, § 21. Nesse parágrafo, Kant apresenta a razão clássica dessa assimilação, pois o predicado singular numa proposição como 'Sócrates é mortal' aplica-se a toda a extensão do sujeito, tal como sucede com os predicados que se aplicam universalmente. É sabido ser exactamente esse um dos pontos que decisivamente distingue a moderna lógica formal, pois não uma tal assimilação não é sustentável.

8 Cf. W. Kneale \& M. Kneale, op. cit., p. 279. 
sair da experiência possível. Quanto à 'unidade colectiva', ela corresponde a um termo colectivo tomado singularmente.

Podemos agora estabelecer o mecanismo subjacente à hipóstase. De um ponto de vista lógico, a hipóstase consiste em passar de uma proposição distribuída do tipo 'todos os homens são mortais' para uma proposição colectiva do tipo 'a humanidade é mortal', na qual o termo colectivo é interpretado como uma entidade singular. Trata-se naturalmente de uma operação ilegítima do estrito ponto de vista do moderno cálculo de predicados à primeira ordem interpretado em extensão, mas o importante aqui é Kant salientar tratar-se de uma operação natural e quase inevitável da razão. Nessa operação, substitui-se o conjunto distribuído - ou agregado de objectos fundados na experiência de cada coisa - por uma totalidade que é uma entidade singular e colectiva, e que é o análogo de uma coisa realmente singular. Esta operação pode ser designada quer como uma substantivização - a realidade distribuída de um termo geral denotando individualmente cada um dos termos da sua extensão é tornada um sujeito colectivo -, quer como uma reificação, isto é, uma entidade abstracta (a 'humanidade') é tomada como uma coisa ou análogo de uma coisa.

O mecanismo da hipóstase necessário para uma completa elucidação da ilusão transcendental fica assim completamente elucidado? Kant descreveu uma operação lógico-linguística tornada possível por um automatismo simples do pensamento simbólico. Mas esta 'conversão linguística' subjacente à geração de entidades imaginárias como o ens realissimum dá de facto conta dos mecanismos reais presentes? A colectivização de uma realidade distribuída é de facto linguísticamente 'natural', mas qual o verdadeiro fundamento real dessa substantivização? Não se dará o caso de esse fundamento operar a um nível mais 'profundo' que o nível lógico-linguístico, e que expressões como 'unịdade distribuída' e 'unidade colectiva' deverão ser separadas do seu sentido lógico? É nossa opinião que Kant não responde de modo cabal a essas questões, pelo, mantendo a sua ideia central, devemos procurar refazer em bases diferentes a sua explicação da hipóstase e da ilusão natural da razão.

\section{A reformulação do argumento kantiano}

Vimos que o ideal transcendental é um produto da razão. Ele é um produto da capacidade simbólica das faculdades de conhecer, mais exactamente, o ideal transcendental é formada a partir das operações lógicas da Razão, pelo que a argumentação Kant se baseia numa extensão da lógica formal à lógica transcendental da razão. Deve recordar-se que se encontra aqui a nítida linha de separação entre a analítica transcendental e a dialéctica transcendental. No caso da analítica transcendental, parte-se das funções lógicas do entendimento tendo em vista a sua esquematização, através das formas da sensibilidade, na experiência. O pano de fundo das operações do entendimento enquanto faculdade legisladora da experiência é pois o espaço e o tempo, e portanto a geometria. No caso da dialéctica transcendental, os raciocínios lógico-simbólicos acabam por não se reportar à experiência, originando-se os paralogismos, antinomias e ideais dessa dialéctica. Se é claro que, visto no contexto da Metafísica tradicional, o ideal da razão decorre do uso ilegítimo da lógica, parece ser igualmente um facto que, se deixarmos de lado esse quadro, é possível ver como a emergência de entidades singulares ideais, hipostasiadas e imaginárias pode ter como base não a lógica mas sim a geometria.

A hipótese que vamos desenvolver implica superar distinções e barreiras traçadas por Kant entre as faculdades, partindo de dois pontos capitais em torno dos quais gravitam parte dos desenvolvimentos da 'Estética transcendental' e da 'Analítica dos conceitos'. O primeiro consiste em tomar a geometria e não, como fez Kant, a lógica, como origem do mecanismo da hipóstese. Mais precisamente, partiremos do espaço, não espaço como forma da intuição mas, seguindo o espírito do movimento da Crítica da Razão Pura, do espaço enquanto forma da intuição convertido em intuição formal (cf. B 160, nota). Isso vai implicar modificar o sentido das unidades 'distributivas' e 
'colectivas' de Kant O segundo é radicalizarmos, sempre fora do debate kantiano com a Metafisica tradicional, e sempre dentro do quadro geométrico, a finitude humana. Este segundo ponto traduz-se no facto de os indivíduos dotados de representações estarem definidos localmente, tendo uma visão absolutamente limitada pelo seu horizonte de acessibilidade, situação de que decorre a sua necessária incapacidade em antecipar as consequência a larga escala das suas acções. Isso implica que, de facto, as coisas em si lhes são absolutamente inacessíveis. No entanto, tal como Kant sublinhou, essa condição de finitude vai gerar a reafirmação da existência de entidades imaginárias.

Para aclarar esses dois pontos partimos de um exemplo. Devemos desde logo salientar que em nada nos importa aqui até que ponto o modelo por ele descrito captura com exactidão a realidade que ele procura modelar. $\mathrm{O}$ importante consiste em não nos deixarmos prender pela sua especificidade, antes salientando que esse modelo visa ilustrar os mecanismos gerais de formação de entidades singulares através do que designamos mais abaixo por explicações míticas, as quais exibem um mecanismo susceptivel de explicar o fundamento da hipóstase kantiana.

A intuição formal de que partimos é constituída pelos autómatos celulares. A moderna teoria dos autómatos celulares foi sistematizada por S. Wolfram nos anos oitenta do século passado 9 . Um autómato celular não representa o mero diverso do espaço fenomenológico dado na sensibilidade mas sim um espaço topológico que consiste numa rede com 1, 2, 3 ou mais dimensões, e composto por certos elementos, os autómatos, que interagem entre si. Os autómatos assumem valores discretos, e o estado de um autómato no tempo té determinado pelo seu estado no tempo $t_{-1}$ e pelo estado em $t_{-1}$ de outros autómatos vizinhos. O número de autómatos com os quais cada autómato interage constitui o raio de vizinhança da rede, e esse raio é igual a 4, ou então, como no caso abaixo apresentado, igual a 8. Os autómatos são pois definidos localmente. Mais precisamente, a dinâmica de um autómato celular é a seguinte: sendo $\mathrm{a}_{\mathrm{i}}(\mathrm{t}) \mathrm{o}$ valor do estado do autómato $i$ no passo temporal t, e podendo cada autómato assumir $k$ valores finitos, os valores do estado do autómato evoluem de acordo com a seguinte equação:

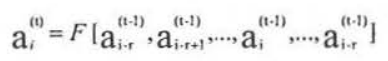

onde $\mathrm{F}$ é uma função que especifica a regra seguida pelo autómato e $r$ é um parâmetro que dá o 'alcance' ou raio de vizinhança da regra, isto é, quantos autómatos vizinhos determinam o valor de um autómato definido como centro desse raio. Esta é a estrutura topológica geral de uma rede de autómatos celulares bem como dos indivíduos que nela interagem. O tipo específico de topologia depende essencialmente da dimensão do sistema e do valor do raio, $r$, de vizinhança ou número de autómatos que interagem com um autómato dado. Essa constrição deve de novo ser sublinhada: cada autómato é 'míope', tendo apenas uma visão do sistema dada pelo seu raio de vizinhança (o qual é o mesmo para qualquer outro da autómato).

Essa estrutura topológica permite modelar um grande número de fenómenos de natureza específica diferente. A fim de mostrar como podem emergir hispostaticamente certas entidades singulares e imaginárias escolhemos aqui um modelo particular, referindo-se de novo que no presente contexto é completamente irrelevante a sua veracidade empírica. Trata-se um modelo que, no seguimento de uma ideia original de Thomas Schelling ${ }^{10}$, implementámos computacionalmente ${ }^{11}$.

9 S. Wolfram, Cellular Automata and Complexity-Collected Papers, Addison-Wesley, Reading, 1994.

10 T. Schelling, 'Dynamic Models of Segregation', Journal of Mathematical Sociology, 1, 1971, pp. 143-186.

11 Cf. Alves, C., Machuco Rosa, A., Antão, A., N., 'Distributed Causation and Emergence in Finite Models', Interact, 1, 2001: http://www.interact.com.pt/. 
Essa implementação consiste numa rede composta por elementos indiferentemente designados por autómatos ou agentes e que podem assumir dois estados possíveis correspondendo à sua 'raça' ou cor: cada um deles ou é $\mathrm{C}$ (Cinzento) ou $\mathrm{B}$ (Branco). O comportamento de cada agente é local, o que significa que cada um é influenciado e influencia oito agentes vizinhos $(r=8)$. Essa 'influência' pode ser entendida como uma 'incitação ao movimento', isto é, cada agente possui 'movimento' e desloca-se (ou não) da sua posição para uma outra em função da proporção de indivíduos da sua cor que se encontram no seu raio de vizinhança. Podemos estipular o valor de $37 \%$ de número de agentes vizinhos como a condição de preferência que leva, ou não, um agente a mover-se. Mais especificamente, o algoritmo que concretiza o modelo de Schelling é enunciado pela seguinte regra de transição dos estados dos agentes:

- Cada agente calcula o número de vizinhos da sua cor.

- Se esse número é superior a $37 \%$ (se menos de $37 \%$ dos seus vizinhos são da sua cor, isto é, se mais de $63 \%$ são de cor oposta), ele move-se para um outro local aleatoriamente escolhido que satisfaça essa condição de preferência; caso contrário, permanece no mesmo sítio.

E é tudo. Trata-se de facto de um algoritmo particularmente simples ${ }^{12}$. Na nossa implementação partimos de um população inicial aleatória de agentes. O resultado final das iterações do algoritmo acima enunciado conduz a um estado final de completa ou quase completa segregação: existem regiões apenas ocupadas por C's separadas por regiões apenas ocupadas por B's (veja-se a figura).
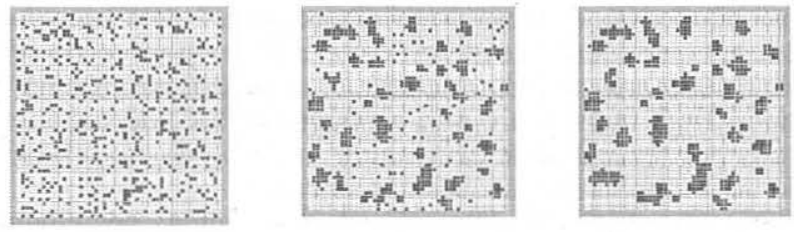

Figura. $\mathrm{O}$ modelo de Schelling definido numa rede com 50 * 50 agentes, com 509 cinzentos e 1991 brancos. O primeiro diagrama representa uma distribuição aleatória inicial. $O$ segundo o estado do sistema após 45 iterações. $O$ terceiro o estado final invariante atingido após 201 iterações.

É absolutamente crucial notar que os agentes do modelo são todos interdependentes e que eles interagem não linearmente ${ }^{13}$. Isso tem como consequência que a análise local do modelo, tomando isoladamente cada uma das suas partes, não permite prever a sua evolução futura. Essa é a situação dos agentes que o modelo é suposto representar: como se supõe que eles são míopes, segue-se que eles apenas podem representar partes isoladas do sistema e portanto qualquer um deles jamais pode prever

$12 \mathrm{O}$ modelo pode ser integralmente descrito pela aplicação: $\mathrm{X}_{t+1}=f\left(\lambda, \mathrm{X}_{1}\right)$, onde $\mathrm{X}$ é o vector de estado do sistema, $f$ a função ou regra específica utilizada e $\lambda$ um parâmetro que traduz a direcção (eventualmente aleatória) em que cada autómato se move.

13 Dito de forma intuitiva, um sistema é linear se podemos analisar cada uma das suas partes independentemente, e de seguida obter as propriedades do todo somando as propriedades de cada parte tomada isoladamente. De forma um pouco mais precisa, diz-se que uma função é linear se o valor da função, para qualquer conjunto dos valores das suas variáveis, for uma média ponderada desses valores. Se essa condição não se verifica, a função não é linear. Os sistemas não lineares são os sistemas em que é necessário tomar em conta as interacções entre os seus elementos para compreender as propriedades que delas resultam; são os sistemas em que o 'todo é maior que a soma das partes'. 
qual irá ser o estado final para que esse sistema eventualmente converge. Os agentes são completamente finitos, devendo notar-se que convertemos uma condição de finitude baseada numa forma da intuição numa finitude decorrente de uma topologia enquanto intuição formal. Essa conversão permite-nos a nós, observadores exteriores, uma análise de certas propriedades do modelo, mas já os agentes que nele interagem possuem um horizonte de acessibilidade completamente limitado, não podendo representar qualquer totalidade, qualquer estado global. Essa totalidade ou estado global é uma coisa em si que lhes é absolutamente exterior. Portanto, qualquer agente não é capaz de antecipar as consequências das suas acções. Mas já se poderia prever (logo, provar) aquilo que as simulações computacionais claramente mostram: o estado de completa integração corresponde a uma situação instável, enquanto o estado final de segregação corresponde a um ponto fixo estável ${ }^{14}$. Portanto, a partir de um estado aleatório inicial, um padrão ou ordem global emerge, sem que, repita-se, isso possa ser deduzido a partir do comportamento isolado de um agente ou de um subconjunto da totalidade de agentes do modelo.

O exemplo apresentado não exibe todo o mecanismo que gera aquilo que vamos definir como uma explicação mítica. Contudo, ele já começa a apontar para essa definição, visto indicar que a explicação mítica é, de facto, em certo sentido ilusória e imaginária. Repete-se uma vez mais não estarmos a sustentar que o modelo é empiricamente plausível, pois interessa sobretudo sublinhar que ele ilustra um processo dinâmico em que o estado final de segregação é o agregado ou efeito 'não intencional' de múltiplas interacções não lineares - não intencionalidade perfeitamente marcada pelo facto de os agentes seguirem uma regra que não é segregacionista. Qual é então a causa da segregação? Em certo sentido, pelo menos no sentido mais usualmente atribuído ao conceito de causa, essa causa não existe. A causa propriamente dita é uma propriedade distribuída que não reside em qualquer parte identificável e decomponível do sistema e que, portanto, não poderia ser representada por qualquer agente desse sistema. No modelo apresentado, o estado final mais não é que o resultado das interacções entre esses agentes. Designamos por 'causalidade distribuída' um tipo de causalidade em que a causa é o agregado de múltiplas interacções não lineares.

Utilizámos pois uma expressão, 'causalidade distribuída', semelhante à expressão 'unidade distribuída' que vimos ser fundamenal na argumentação de Kant. Na verdade, a alteração do sentido do conceito ‘distribuído' marca a própria modificação que fazemos do ponto de vista do filósofo alemão. Nós baseamo-nos explicitamente na moderna teoria dos sistemas complexos ${ }^{15}$, aqui desenvolvida no espaço topológico discreto dos autómatos celulares, enquanto Kant se baseava na lógica e metafísica clássica. Em Kant, vimos que a unidade distribuída não era realmente uma entidade distribuída no sentido de um conjunto de interacções locais que fazem emergir uma estado global invariante completamente exterior a cada uma dessas interacções, mas sim a aplicação de um termo geral às suas instâncias. Resta ver como, no quadro topológico e geométrico, emerge uma 'unidade colectiva'.

Kant salienta que a hipóstase tem como primeiro fundamento a coisa, o real que nela é dada, e de seguida o real como matéria da presença em geral. Sem fazer intervir uma entidade global como é o 'presente em geral' - que no entanto não permite aceder a qualquer coisa em si - seguimos uma argumentação paralela partindo das interacções locais, as quais são reais no sentido kantiano. Temos de partir de algo que efectiva-

14 Um ponto fixo de um sistema é o estado final invariante que resulta da evolução dos elementos desses sistema. Assim, por exemplo, no modelo de Schelling, é o estado final que não se altera mais por iteração do seu algoritmo. Formalmente, o ponto fixo de uma transformação T é um ponto, $\mathrm{x}$, tal que $\mathrm{T}(\mathrm{x})=\mathrm{x}$.

15 Como a teoria dos sistemas complexos não existe, não é possível referir qualquer obra de síntese. Para uma visão parcelar, o leitor poderá talvez consultar J. Casti, Complexification, HarperCollins, New York, 1994; P. Bak, How Nature Works, Springer, New York, 1996. 
mente podemos experienciar. Ora, viu-se que de facto não é possível experienciar uma propriedade ou causalidade distribuída.

Não estamos habituados a associar a causalidade distribuída aos tipos de causalidade. Uma lista dos tipos de causalidade foi identificada por Aristóteles. Nela não figura algo correspondente ao que designamos por causalidade distribuída, o que não deve surpreender visto que, repita-se, não a podermos experienciar directamente. Pelo contrário, existe um tipo de causalidade que podemos experienciar directamente e que em certo sentido nos é plenamente inteligível, a causalidade eficiente, definida como a coisa ou agente responsável pela mudança na forma de uma outra coisa. A causalidade eficiente é um tipo de causalidade local, e ela está presente na interacção com 'a coisa' e o 'real' de Kant. A hipótese aqui desenvolvida consiste em ela ser o tipo de causalidade que serve de fundamento ao processo de formação de entidades imaginárias singulares susceptíveis de serem responsáveis por uma certa ordem global (por uma certa totalidade). É nisso que consiste a substituição e explicação mítica. Esta é um processo de busca de inteligibilidade e explicação dos fenómenos quando a sua inteligibilidade global nos é absolutamente inacessível. É o que sucede num processo distribuído, o qual jamais pode ser representado por qualquer dos indivíduos que localmente para ele contribui. Sustentando-se que a causalidade eficiente aristotélica é primária e absolutamente inteligível, no sentido em que temos uma experiência directa desse tipo de causa, segue-se que qualquer tipo de causalidade que não é nem pode ser dada numa experiência directa - numa interacção real - será reduzida a essa causa. Designamos por explicação mítica e fundamento da ficção de entidades singulares imaginárias a substituição de uma causalidade distribuída por uma causa operando segundo o modo de uma causa eficiente. Noutros termos, essa substituição é o mecanismo subjacente à hipóstase kantiana, à substituição da 'unidade distributiva' pela 'unidade colectiva'.

Para tornar mais claras as implicações da definição precedente, podemos recorrer de novo ao modelo de Schelling como ilustração. Vamos supor, de novo, que uma causalidade local e distribuída conduz a um estado final invariante de segregação. A ser assim, a segregação apareceria a cada indivíduo segregado como uma ordem global dada. Podíamos então perguntar a um deles: 'O que pensa ter sido a causa deste estado de segregação?' Seguramente que se acordará ser completamente implausível uma resposta do tipo: 'Parece ter sido gerado pela acumulação das acções de muitos individuo miopes, todos eles não segregacionistas'. É mais plausível pensar que a resposta seria: 'a nossa comunidade assim decidiu', ou 'cada um de nós assim decidiu porque não gostamos deles e não os queremos por perto'.

Deve-se notar, em primeiro lugar, que esse tipo de resposta supõe o uso de uma regra de maioria quando é uma regra oposta que de facto é responsável pela dinâmica do modelo de segregação. Em segundo lugar, o ponto importante reside no uso de pronomes como 'nós', tal como a menção da entidade colectiva e singular 'a comunidade'. No caso do primeiro tipo de resposta, aponta-se para a substituição de uma causalidade local e distribuída (que ninguém pode experienciar), por uma causa única e global (a 'comunidade') que completamente satisfaz a inteligibilidade pois essa causa global funciona segundo o modo de uma causa local, isto é, como causalidade eficiente - uma causa que, essa sim, os indivíduos podem experienciar. No segundo tipo, a resposta mostra a substituição de interacções não lineares por uma explicação baseada em interacções lineares - fazendo a soma de comportamentos individualmente segregacionistas -, sendo um facto que qualquer pessoa pode experienciar esses comportamentos. Em ambos os casos, constata-se que a substituição mítica consiste na substituição de uma causalidade distribuída por uma causa singular e global que funciona segundo o análogo de uma causa eficiente. A formação de uma entidade colectiva hipostasiada parte pois do real, mais exactamente, da experiência originária da causalidade eficiente, tendendo a surgir em situações de completa finitude, isto é, em situações em que uma causalidade distribuída está operando. 
A ser assim, podemos compreender mais exactamente como surgem as entidades singulares susceptíveis de explicar a ordem um global de um certo fenómeno: a entidade singular encerrando a determinação completa do fenómeno mais não é que uma causa que reproduz de modo invariante o tipo de causalidade directa - mas não distribuída , só que ela é imaginada como exercendo globalmente sobre o fenómeno considerado o tipo de causalidade que cada objecto exerce directamente sobre cada outro. Naturalmente não estamos a afirmar que os indivíduos fazem 'conscientemente' uma tal substituição, visto se ter insistido não existir uma experiência directa de uma causalidade distribuída, sendo exactamente por isso que a substituição é a substituição da causalidade eficiente real pela causalidade eficiente imaginada como operando segundo o modelo de uma causa eficiente real.

Podemos então recapitular, reformulando-a, a argumentação de Kant. Naturalmente que não the era claro que o conceito de causalidade distribuída podia ser convertido numa intuição formal. Ora, viu-se que a análise geométrica e computacional desse tipo de causalidade mostra que um sistema converge endogeneamente para um ponto fixo. Este tipo de dinẩmica pertence seguramente à 'Analítica transcendental' kantiana. A passagem à dialéctica transcendental reside no facto de se ultrapassar a radical condição de finitude hipostasiando uma entidade singular que está em definitivo para além do horizonte de acessibilidade e que é uma coisa em si não representável geometricamente: através do mecanismo de substituição mítica descrito, o ponto fixo endógeno é hipostaticamente convertido numa entidade exógena e absolutamente exterior a todos e que é tornada responsável pela determinação completa da dinâmica. Essa entidade é um ser singular que mais não é que a ficção de uma ideia in individuo imaginada como existente devido a causalmente gerar a totalidade da realidade. É, estritamente, a reificação imaginária numa totalidade de uma realidade distribuída. Como é conhecido, Kant referiu (A 583 / B 611, nota) que essa entidade corresponde, na metafísica clássica, a um 'ser soberanamente real', que, primeiro, é 'tornado um objecto', que age de seguida eficientemente como uma 'pessoa' e que, finalmente, adequa meios a fins ao modo de uma 'inteligência'.

Noutras ocasiões analisámos múltiplos exemplos que substanciam as anteriores conclusões $^{16}$. Essa análise mostra sempre que o mecanismo no qual radica a formação do ideal transcendental consiste sempre na substituição da coisa pelo análogo imaginário da coisa, transcendendo, tal como Kant de facto sublinhou, numa causa exterior aquilo que é pura imanência. Kant fundamentava essa substituição numa conversão lógica e linguística - passagem de um juízo lógico distribuído a um substantivo colectivo coisificado, tal como 'a humanidade é mortal'. Não se procurou esclarecer aqui o totalidade do fundamente dessa substituição lógica, a qual provavelmente emerge a partir da estrutura da linguagem pensada como uma entidade natural reflectindo os tipos de causalidade de que os agentes são capazes. Mas já se procurou sustentar que essa substituição linguística reenvia para a situação teórica, cognitiva ou comportamental de indivíduos enredados numa realidade distribuída cuja dinâmica global eles jamais podem representar. Desconhecendo a dinâmica complexa que conduziu a um certo estado de coisas, eles produzem uma realidade que a todos transcende e que é transfigurada numa coisa operando ao modo de uma vontade e inteligência que reifica a forma dada segundo a qual a realidade lhes aparece. É ter identificado este processo substituição que constitui a marca do génio de Kant. Mas é também por, inevitavelmente, o ter feito depender em demasia do estado do conhecimento do seu tempo que o impediu de completamente identificar a dinâmica que se lhe encontra subjacente.

16 Cf. A. Machuco Rosa, Dos Sistemas Centrados aos Sistemas Acentrados - Modelos em Ciência Cognitivas, Teoria Social e Novas Tecnologias, Lisboa, Vega, 2002; A. Machuco Rosa, 'Complex Systems, Imitation and Mythical Explanations', submitted to Contagion: Journal of Mimesis, Violence and Culture. 